\title{
Design and Implementation of a Comprehensive Educational Model: Project Based Engineering School (PBES)
}

\author{
http://dx.doi.org/10.3991/ijep.v5i3.4673
}

\author{
M.J. Terrón-López, M.J. García-García, P.J. Velasco-Quintana, M.C. Gaya-López and J.J. Escribano-Otero \\ School of Architecture, Engineering and Design, Universidad Europea de Madrid, Spain
}

\begin{abstract}
The School of Engineering at the Universidad Europea de Madrid (UEM) implemented a change in the pedagogical model applied in its degrees at the 2012/2013 period: the "Project Based Engineering School" (PBES). It consists on the application of the Project-Based Learning (PBL) methodology in at least several subjects each course in all its degrees. Each academic year, the students develop a capstone project covering partially the content of several subjects; faculty board and teachers were involved in the designing of a global framework and implementation adapted to each degree. How this process was made is explained in this paper. Positive results were obtained at the end of the first year that include further development of key skills, a deeper understanding of the specific skills and an increase on the motivation of students and teachers. There were also identified some areas for improvement for the coming years. This article will also show some of those results (both qualitative and quantitative) obtained after a year of experience from the students' point of view.
\end{abstract}

Index Terms-Capstone projects, coordination, methodological change Project Based Learning.

\section{INTRODUCTION}

Science, technology, engineering and math (known as STEM) are fields which have been, and are still, key to human development. However, despite the great need of graduates from these fields, school dropout of students in these areas is increasing. There are many factors associated with school dropout, among them, Herrera \& Lens [1] mention student's socio-economic difficulties and school failure due to class repetition or limited classroom learning. Additionally, descriptive studies done by different authors report, as another factor, high class nonattendance [2]. In recent years we have learned that the classical lecture-based method of teaching, in which the teacher speaks and the students only listen, provides few opportunities to actively involve students in solving real world problems and, in this way, increase their interest and motivation. In fact, this traditional method of teaching has been connected to low student motivation, which has also been linked to student learning and school attendance [3].

Motivation is a force that energizes, directs and sustains students' behavior. We often see this motivation reflected on personal investment and a cognitive, emotional and behavioral engagement in school activities [4]. According to Maehr \& Meyer [5], motivation directs the behavior of people towards specific goals, so that motivation affects the choices students make. This means that a motivated student increases the amount of effort and energy spent in activities directly related with their needs and goals. Therefore motivation determines if a student carries a task with enthusiasm and without reservation or with apathy and reluctance. According to Ormrod [6], motivation increases the persistence shown by students to complete activities they start, despite being frustrated by problems in the process or the difficulty of the task. This characteristic is crucial in students that pursue careers in engineering, where they must overcome difficult subjects and require a behavior that allows them to meet goals by displaying great effort, energy and perseverance.

A way to increase student motivation is changing how engineering is being taught, making it more relevant and interesting for students [7]. In the literature we find that for students to experience real learning is necessary for them to construct their knowledge from knowledge they have acquired previously in other places or having them work in a problem which is interesting and compelling [8]. In summary, using an active learning methodology that allows students to work in the context of problems and projects has become a necessity.

One of these active learning techniques that appears as an alternative and answer to a series of problems related with engineering teaching is Project-Based Learning (PBL) which organizes learning around projects [9]. These projects will involve students in design, problemsolving, decision making culminating their learning in realistic products or presentations $[10,11]$.

\section{OBJECTIVES}

\section{A. The context}

The School of Engineering at Universidad Europea Madrid (UEM) offers the following different degrees in four fields of study (Information and Communication Technology -ICT-, Industrial, Aerospace and Civil Engineering):

- Bachelor's Degree in Computer Engineering

- Bachelor's Degree in Telecommunications Systems Engineering

- Bachelor's Degree in Audiovisual Systems Engineering

- Bachelor's Degree in Biomedical Engineering

- Bachelor's Degree in Mechanical Engineering

- Bachelor's Degree in Energy Engineering

- Bachelor's Degree in Organizational Engineering 
- Bachelor's Degree in Industrial Electronics and Automation Engineering

- Bachelor's Degree in Aerospace Engineering

- Bachelor's Degree in Civil Engineering

To obtain one of these degrees students have to complete 240 ECTS (between 36 and 48 subjects, including university core requirements, degree requirements and electives) in four years.

There are also double degrees that combine some of the Engineering degrees with Business Management and Entrepreneurship degree. These programs are longer (between 318 and 342 ECTS).

Each academic year, for all bachelor degrees, is organized in three quarters. This allows the students to focus on only few subjects (from 3 to 5) each quarter but also they have to dedicate more work-time on the subjects.

As in other engineering programs, we faced the important problem due to the lack of motivation of first year students, which often results in high rates of students' dropout. This can be due to the teachers' dependence on a theory based science model. However this model does not prepare students for being engineers and this is one of the greatest criticisms of traditional engineering pedagogy where the traditional lecture based teaching is used [12]. Students then perceive a large theoretical load without applications to what they thought they were going to learn. Lecture based teaching not promote active learning among students. Students do not understand how all this theory explained in the classrooms is connected with the engineering world where they intend to work. Therefore, they are not able to incorporate their learning to them. They don't achieve a deep and significant learning. In this context, in which, it was decided to make a change of teaching methodologies and approach globally in our engineering school.

\section{B. Objectives}

It was intended to build our own Project-Based Engineering School (PBES) as we knew that the main goal of the project based learning methodology (PBL) is to offer students a chance for practical learning in a supported environment that will facilitate the transfer of knowledge from the educational environment to the professional one [13].

In designing and implementing our PBES we wanted to achieve the following objectives:

- To increase motivation and pride of belonging of students and teachers, placing in the center not only the students' interests but also teachers'.

- To achieve a deeper learning by applying active methodologies, integrating the fundamental knowledge and the specific skills needed in the training of an engineer, and as a result, an improvement in the academic performance of our students.

- To develop and promote generic skills such as teamwork, oral and written communication, independent learning, planning and time management.

- To approach the classroom to the profession (and vice versa) acquiring the knowledge while practical and real problems are solved.
- Focus on the social, economic and environmental sustainability as a key skill that every engineer has to develop.

- Encourage entrepreneurship, technological innovation and internationality.

\section{DESCRIPTION OF THE WORK DONE}

\section{A. Implementation Phases}

This section explains the phases followed for designing and implementing this PBES and its key characteristic.

1st phase: General design. During the last quarter of the academic year 2011-2012 several working sessions were carried out. The purpose of this first phase was to decide a specific and unified personality for the School and to establish the general framework to be adopted in all the programs.

Extraordinary meetings of the engineering school faculty board were held to design this new desired profile of the school.

From these sessions we decided that to be an engineering school based on the methodology of projectbased learning (PBL), we needed to implement a project in each course of all the degrees of the School of Engineering. Therefore, the design and implementation of capstone projects must be done for each year of study including several subjects; also the project must be adapted to the students' year of study and it is necessary to link the project to the professional community needs.

Academic Director, Managers of Academic Programs and Academic Coordinators established periodical meetings in order to define the general guidelines of the capstone projects to be developed in each degree.

Projects designed using the PBL methodology would serve as the cornerstone to enable students to acquire, to integrate and to apply knowledge of various subjects. Also the design would give priority in the practical application of the subjects. Another conclusion from the working sessions was to propose more realistic work context created for the PBL environment related to the industry, thus the more realistic project the more value PBL. Additionally, project design must include the development of entrepreneurship, social, economic and environmental sustainability and technology innovation. The project was designed in a way that the technical and cross-disciplinary skills were developed progressively in various subjects starting from the first quarter.

2nd phase: faculty information and training. At the end of the year, sessions with all faculty members and the Academic Director were held. The objective of these sessions was to inform and describe the new profile and general outlines of the projects to faculty.

However, teachers weren't able to implement all this by themselves without training. Therefore, as we wanted to assure that teachers clearly understood the methodology, teacher training programs regarding PBL were offered to the faculty in this second phase. This program consisted of:

- 20 hour online introductory course to Project Based Learning (PBL)

- 11 summer lectures regarding PBL and the new profile the school wanted to achieve 
- Two workshops with experts in PBL implementation: Dr. Moesby from Aalborg University (Denmark) and Dr. Valero from the Polytechnic School of Cataluña (Spain). The aim of these workshops was to share successful experiences implementing PBL.

3rd phase: definition and coordination. Periodical meetings of faculty were scheduled. The aim of those meetings was that teachers of each degree could work together in order to define the structure and general guidelines of each one of the different projects that were going to be developed. Every meeting was leaded by the academic program director of the bachelor degree. The department chairs were also involved.

Coordination is a key [14] whenever a change in teaching methods is wanted to be made. To facilitate that coordination, a form was designed for gather the main elements of each capstone project. The form has the following fields:

- Bachelor Degree

- Name of the project

- Year-course of study

- Project coordinator Name

- Project description

- Project Objectives

- Courses involved in the Project

- Intended Workshops, tour to companies, master classes, or others

- Technical and Transversal skills to be developed

- Level of expected development in each of the following five elements:

a. Connection to the real world

b. International

c. Sustainability

d. Entrepreneurship

e. Technology innovation

- Assessment Procedures and tools

- Schedule of the project

In these coordination meetings, it was also identified the need of a teacher as a project coordinator. This coordinator will be in charge of assuring the project implementation and its monitoring in all its phases.

A need of resources was also detected. Therefore a virtual a platform was created in the virtual campus for those teachers involved on the capstone projects, as well as for their head of the departments to monitor the projects. All project materials such as meeting minutes, action plans, analysis of the results and reports are available on the virtual campus for the faculty. Anything related to these projects was uploaded here as well as some tools to assess key skills [15, 16, 17, 18].

During these meetings between teachers, academic program directors and department chairs, the project coordinators were selected, the proposals for each capstone project were defined as well as the subjects and courses involved on it.

As a result, a general framework and specific conditions for each project were established to start with the implementation of the PBES in the 2012-2013 academic year. First approach was to set up integrating projects only designed with subjects of the same year (horizontal integration), thus the vertical integration subjects (from different years) are not taking part to this first phase implementation. Next step of implementation would be to design the project including vertical integration subjects, although a pilot project with vertical subjects was set up for aerospace engineering degree.

These subjects could be at the same quarter or be from different quarters depending on their schedule within the academic year and the area of knowledge of the project. As part of this methodology, the student would perform the projects on. It could happen that some students are not registered for all courses involved in the project. Thus, to participate on the project the student must register on one of the courses of the project and only perform the activities of that one.

$4^{\text {th }}$ phase: development. Once established the common framework and the specific conditions of each project, next step was to move forward to the operational phase.

At the beginning of the 2012-2013 year, the Dean and the Academic Director presented to students the general framework of the Project Based Engineering School. Teachers of the subjects involved in capstone projects explained to the students the overall objective of the project and the specific objective to be achieved during the subject.

During the year, a variety of actions were scheduled to ensure the success of the new approach:

- Specific working sessions of each project (conducted by the project coordinator).

- Follow-up sessions by academic director.

- Follow-up sessions by engineering school board.

Finally, a closing and award ceremony of PBES would be scheduled at the end of the academic year to award the best project by year-course of study and bachelor degree.

$5^{\text {th }}$ phase: evaluation. As a final phase, we wanted to measure PBES's effectiveness in achieving its objectives. Therefore, various mechanisms of control and measurement were designed to be applied after each year:

- To evaluate the students' perceptions:

- Design of a survey that included both close-ended questions (with Likert-type scales) and openended questions (to allow the comments of the students).

- Semi-structured interviews with students: we decided to carry out interviews with several groups of selected students to ensure the diversity of student's profiles.

- To evaluate the teachers' perceptions: semi-structured interviews in order to detect both best practices and areas of improvement.

- To compare students' academic results before and after the implementation of the PBES: Data sheets to analyze the final marks of the students in different academic years.

- To analyze the students' satisfaction: it was decided to review the results of the institutional surveys of satisfaction with the teaching of the subjects involved. 
From these data we intended to collect both the perception of the actors involved and quantitative data that could guide us every year on improving the new model.

\section{B. PBES Implementation}

As we have seen, to implement our PBES, several working sessions were carried out with the initial purpose of establishing the general framework of the project. From these meetings a roadmap was established to implement the global change designed for the School and the necessary decisions to adapt the overall change in each of the years of study of the engineering degrees taught. The subjects to be included in the change were selected and the capstone projects were organized in order to allow that every student, every year, undertakes at least one project which integrates the knowledge and skills needed to develop a specific final product associated to those courses. A project coordinator was assigned to each capstone project to assure the implementation and monitoring of the project in every phase. At the end of the academic year each project coordinator selects the best projects submitted by students. This selection will be presented in a special session where some companies involved are invited as a jury to choose the best one of this year.

Project coordinators should guarantee that the projects include the elements needed to get the PBES objectives. That means that capstone projects try to solve a real problem in a specific company or at least closes the gap between the class and a real application in the specific profession. On the other hand, the projects should allow students to focus on some aspects of sustainable engineering projects, and their implications for environmental surrounding and society. As part of this methodology, the student would perform the projects on teams.

The final product developed by each group of students must be assessed by a committee. The committee was formed by the teachers of the subjects that are part of the capstone project. Teachers evaluated the presentation and the product produced by each team. The mark obtained was part of the score of each student in those subjects as it was explained in the capstone project form, where the procedures and tools to assess it were indicated, as well as the extent to which that mark was reflected in the assessment of each of the subjects that composed the project.

\section{Closing and award ceremony.}

Among the best evaluated projects by the project coordinators, an expert committee selected the three finalists for each degree. The committee was formed by the academic director, the manager of the academic program and the dean.

The teams selected as finalists were asked to produce a video that had to last less than 3 minutes. This video was presented in the final session where company representatives attended.

The final session took place at the end of the year. The main objective of that session was to choose a winner among the best projects developed in each degree. Other goals were to present the methodological change that had been done jointly in all degrees to the companies, and to celebrate the good work done by the students and the teachers, and the success of the new framework in the School.

The evaluators were representatives of several leading companies in the sectors of reference for qualifications. The final product developed in each team was exhibited and the video generated was presented. On this base, the companies of the corresponding area selected the winner, the best project among the finalists in each degree.

During the final cocktail, after the award ceremony, the companies' representatives, teachers and students interacted and new ties were created for work together in the following years.

The videos produced by the student and some other significant results can be seen at the website of the Universidad Europea de Madrid Engineering School (http://politecnica.universidadeuropea.es/proyectos/PI)

\section{PBES in figures}

During the first year of implementation, 2012/2013, 26 capstone projects were designed for all the engineering degrees taught at the School. The subjects that were part of these projects were 67; each project was connected with two to four different courses. The teachers who taught those subjects were 55. Some of them were in charge of more than one subject and therefore participated in more than one capstone project. The total amount of students of the school involved in the realization of these projects was 653. There was only one company that took part of the definition and development of one capstone project, helping the students and teachers during the development. In the final session, there were 11 companies participating.

The second year of implementation, 2013/2014, there were 30 capstone projects designed, involving 70 different courses, 700 students and 12 companies.

It is too early to analyze the data of the third year of implementation, but the results obtained so far are very promising and allow predict that the desired progress in the implementation of the model is going to be achieved.

\section{RESULtS}

This section of the article focuses on the results after the first year of implementation. We got up data through surveys and interviews with students. We will also focus on the marks obtained and the results of the institutional survey of satisfaction with the teachers.

The surveys and interviews with students and faculty were conducted between June and July 2013, extracting results that have served for the design of the second year of implementation of the Project-Based Engineering School in the 2013-14 year.

The analysis of marks and results of satisfaction with the teachers were obtained later and helped us to confirm the overall improvement obtained with the new framework.

\section{A. Survey.}

The student's survey has three parts.

The first one is an introduction for the student where the goals of the surveys were introduced and the openness was required. The second part is composed by several preliminary questions that provide us a way to determine the profile of the students. We needed to know if the student was involved in one or more projects, if he or she 
was enrolled in all the subjects of the project or not and the year and degree that he or she belongs to.

Table I shows these two sections of the survey.

TABLE I.

INTRODUCTION AND PRELIMINARY QUESTIONS OF THE STUDENT'S SURVEY

\section{Your opinion about the capstone projects}

This survey is anonymous and aims to collect feedback from students regarding the capstone projects developed between several subjects, in order to improve its implantation next academic year. Answer it sincerely.

\section{PRELIMINARY QUESTIONS:}

Answer these questions regarding your profile.

1. Number of integration projects in which have been involved:

2. I was enrolled in all courses which were part of the projects I've been involved (yes / no):

3. Some of the projects that I have been involved lasted more than three months (yes / no)

4. Upper year in which I am enrolled (1/2/3/4)

5. Degree:

- Bachelor's Degree in Computer Engineering

- Bachelor's Degree in Telecommunications Systems Engineering

- Bachelor's Degree in Audiovisual Systems Engineering

- Bachelor's Degree in Biomedical Engineering

- Bachelor's Degree in Mechanical Engineering

- Bachelor's Degree in Energy Engineering

- Bachelor's Degree in Organizational Engineering

- Bachelor's Degree in Industrial Electronics and Automation

Engineering

- Bachelor's Degree in Aerospace Engineering

- Bachelor's Degree in Civil Engineering

6. This is the first year that I am in this university (yes / no):

7. If the answer to 6 is no

My results have been better this year than in previous years (yes / no):

The third part is the survey itself and it is shown in Table II. A Likert scale has been used (1 for strongly disagree and 5 for strongly agree). This section was designed to evaluate the achievement of the main goals on the new Project Based Engineering School, shown in section II.B of this article. After each question, an open space allowed the survey respondents to express their own opinion over the topic.

The first and second questions have been used to know the student's motivation. We wanted to answer to the key question 'Does this methodology promote the student motivation?' The third and fourth respond the key question 'Are the capstone projects similar to future professional projects? The fifth responds the question 'Has this methodology obtained a deep learning on specific skills?' Lastly, the sixth and seventh ones respond the question 'Does the student develop soft skills?'
The response rate was very high. The survey was launched to all the students that have participated in the capstone projects, and $62.7 \%$ of them give their answers.

Profile of the students. For $50 \%$ of the polled students this was their first year in our university (UEM). More than half of the students $(59.4 \%)$ have participated in a single capstone project, and the rest was involved in two different integrating projects. $75 \%$ of the responses indicate that some of the projects in which the students participate lasts more than three months, and only half of them $(50 \%)$ were enrolled in all the subjects involved in the projects they have participated in. Among the students who were not for the first time in our university and had participated in capstone projects, $75 \%$ indicated that their results this year had been better than in previous years.

Achievement of objectives. The scale used to collect information in the rest of the items was a Likert-scale which consists of the following values: $1=$ Strongly Disagree, $2=$ Disagree, $3=$ Neutral, $4=$ Agree, $5=$ Strongly Agree.

Below are detailed the questions and the mean of the responses at each one:

1. I've been more motivated in subjects involved in a project than the subjects which are not involved in: 3.5

2. Participating in projects has motivated me to continue with the degree: 3.6

3. I believe that the work I have done in the project will be very similar to what I will do in my future: 3.5

4. The development of a project designated to an external company that could commercialize this project in the market, it is a chance for me: 4.0

5. Developing a project has provided me the knowledge and understanding of the technical content of the subject involved in it: 4.1

6. Implementing the project has allowed me to think about the economic, social and / or environmental implications, which are associated with the achievement of my future profession: 3.2

Students are also provided a list of 18 general skills that are part of the catalog of competences used in UEM when defining the skills that have to be developed in the students, and they were asked about each of them. In this kind of questions they also included the response option NS (I do not know) to distinguish the students who did not identify or understand the skill on which they are asked.

TABLE II.

SECTION 3 OF THE STUDENT SURVEY

Select the best answer and record any additional comments you consider appropriate.

1 = Strongly Disagree, 2 = Disagree, 3 = Neutral, 4 = Agree, 5 = Strongly Agree, NS = don't know

1. I've been more motivated studying the subjects covered by the project than others in which this method is not used: with more eager to attend class, I preferred working on the project than in other classroom activities, ...

Comments: 


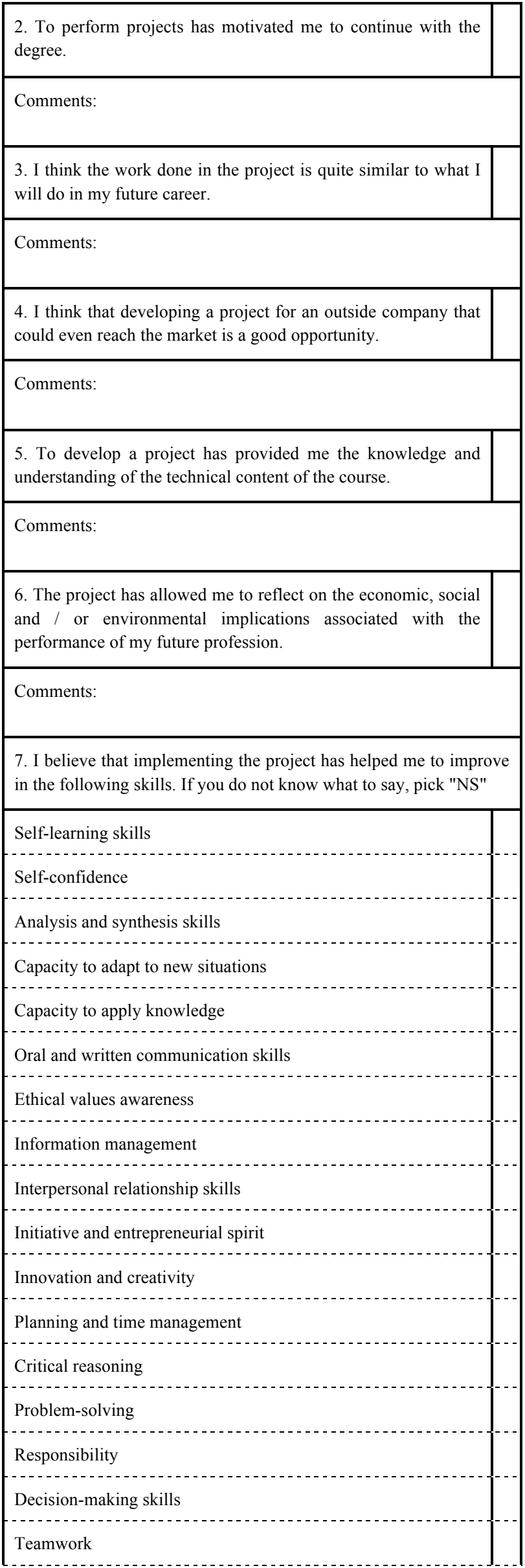

\begin{tabular}{|l|}
\hline Use of information and communication technologies (ICT) \\
\hline Comments: \\
\hline What was the best? \\
\hline What was the worst? \\
\hline How would you improve it? \\
\hline
\end{tabular}

Regarding the question 7: "I believe that implementing the project has helped me to improve in the following skills", the answers are shown below. They answers are shown ordered from the highest score to the lower one:

- Making decisions: 4,0938

- Ability to adapt to new situations: 4,0645

- Use of information technology and communications (ICT): 4,0625

- Responsibility: 4,0625

- Ability to apply knowledge to practice: 4,0625

- Initiative and entrepreneurship: 3,9688

- Analysis and synthesis skills: 3,9355

- Problem solving: 3,9063

- Self-confidence: 3,9032

- Interpersonal relationships Skills: 3,8667

- Information Management (search, selection and integration): 3,8438

- Self learning: 3,8000

- Innovation and creativity: 3,7742

- Teamwork: 3,7188

- Critical reasoning: 3,7097

- Oral and written communication: 3,4839

- Planning and time management: 3,3871

- Conscience of ethical values: 3,1538

Analyzing these results, the most improved skill in the capstone projects (according to students) was making decisions while the worst developed was awareness of ethical values followed by planning and time management. The answer that appears most often in all skills is 4, with the exception of conscience of ethical values which has had 3 (neutral value) as the most often answer. This is clearly a skill for improvement, which can be reinforced in future by making greater emphasis on the study of the social, environmental and economic implications of projects.

\section{B. Group interview.}

From the qualitative analysis of group interview we can deduce the following results:

According to the development of specific skills it is worth pointing out: 
- Self-awareness of learning: students are more aware of what they learn in the year and the level of depth they achieve on it.

- Strengthen the need to learn. With the development of capstone projects students have the opportunity to forward questions related to the specific objectives of the courses in the year, which allows them be alert to the responses (we create expectations) and learn at a deeper level. The student is aware from the beginning. He or she knows which skills the students need to know to complete the project, which skills he or she has, and which ones he or she has not; what make students more active to receive the contents of the subjects.

- Durability of learning. Students perceive that capstone projects and PBL is more powerful method to learn than traditional methods, like exams. The learning is deeper and remains in time.

- Specialization only in a certain parts. One of the inconveniences identified by the students is the specialization of each team member in a particular task of the project.

According to the development of generic skills, students' perception is:

- Teamwork. Students have experience working in teams in labs practices. However, they state that team working in projects is more difficult. They acquire different roles within the team and a better organization and planning is needed.

- Planning. They emphasize the need for good planning to go on the project.

- Responsibility. They give much importance to responsibility. On the one hand they stand for the need for each team member to be always updated with the project development just to avoid delays. On the other hand they describe several situations in which the lack of responsibility of team members provoke excessive workloads for members who want to work and worse academic results for them.

- Communication. Students highlight how important is this skill. It is important for being able to explain the project, to negotiate in the making decision processes, and to carry through the project coordination.

- Self-learning. They consider themselves have had to encourage this ability.

- Sustainability focus. They have developed this skill but in a very tangential way. They have not been aware until this skill was set out in the interview.

In regard to the approach or linking to the professional world, the students indicate:

- Similarity project-professional future. Although it is difficult to predict, they believe that the project looks like their professional future is going to be, at least in terms of development in generic skills. Moreover, most of them highlighted this aspect as their favorite one.

- Distance between project and technical skills associated to the courses. It was raised the concern that the content of the project will stay away from specific skills of the subjects, when filling a real need for an external company. In this respect they say that, in some cases, they need deeper knowledge of specific skills than the level at which it is explained in class.

- Copyrights and Licensing rights of the project. They believe that the fact of working for a project for an external company that eventually can be sold is rather an opportunity. Furthermore, they do not consider that the project may be of sufficient quality to be marketed.

According to motivation:

- Motivation for learning. To work on the project makes them to see the utility of the theoretical subject contents and facilitates them the study, promoting a deeper learning.

- Pride of the result. Students are proud of the project results, and show it to their families and friends.

- Solution to drop-out rates in the first years. They consider projects as a useful tool to show first year students the connection of courses with the degree they are studying.

- Overall view of studies. They believe that the project gives continuity and sense to their studies.

Related to suggestions for improvement, students have detected:

- Distribution of workload: they consider this form of work entails a shift in workload at the end of the subject, so they spend the last two weeks of each quarter very overwhelmed.

- Information for enrollment. They consider that it is necessary to know the courses that are involved in projects before enrolling as they may vary from one academic year to another.

- Assessment. A proposed improvement is that the subjects involved in the capstone project will be assessed based only on the project development and results.

\section{Marks.}

According to the marks obtained by our students, we can say that students had got better ones than in the previous year. In the academic year 2012-2013 percentages of "fail marks" has decreased from $15 \%$ to $10 \%$, while the number of pass has increased from $37 \%$ to $66 \%$. Although we cannot say that these results are attributable only to the implementation of this project, but the results are very promising.

\section{Satisfaction with teachers.}

Finally, the satisfaction with teachers has also increase at the Engineering School, going from 4.0 in 2011-2012 to 4.1 in $2012-2013$ in a $1-5$ scale where 5 was the higher score.

\section{CONCLUSIONS}

The design and implementation of this new methodological framework for a whole school of engineering has been possible only thanks to the involvement of many diverse agents: 
- The university as an institution has provided the means for teacher training

- Faculty board has designed a common model, establishing general objectives

- The faculty has been involved from the beginning, taking part in the initial design of the project, coordinating the implementation thereof and guaranteeing the achievement of learning objectives by students.

Students have positively accepted the methodological change highlighting:

- They feel very motivated by the implementation of this experience.

- They perceive capstone projects as a tool to promote a deep and long-lasting knowledge of specific technical and soft skills.

- The possibility of performing projects with external companies, and the fact that the realization of these projects brings students to professional world; it is very prominent and valued for students.

- Satisfaction with faculty has also risen.

The identified areas for improvement have helped us to get better experiences in subsequent years:

- The participation of companies has increased every year.

- Projects are redefined annually.

- Additional training program focused on the needs of this new methodological framework for teachers.

The good results obtained helped us to continue working on the implementation of this new global methodological model for all school degrees. Our main goal now is to achieve a full project based engineering school.

\section{REFERENCES}

[1] D. Herrera and W. Lens, "Intervención educativa para reducir la deserción e incrementar la motivación en colegios públicos de San José de Costa Rica." Revista de Psicología UVM, Vol. 2, Num. 3, pp. 8 - 29, 2012.

[2] T. Moreira-Mora, "Perfil sociodemográfico y académico de estudiantes en deserción del sistema educativo." Actualidades en Psicología, Vol. 21, Num. 108, pp. 145 - 165, 2007.

[3] S. Devadoss and J. Foltz, "Evaluation of factors influencing student class attendance and performance." American Journal of Agriculture Economics, vol. 78, no. 3, pp. 499 - 507, 1996. http://dx.doi.org/10.2307/1243268

[4] J. A. Fredricks, P. C. Blumenfeld and A. H. Paris, "School engagement: potential of the concept, state of the evidence." Review of Educational Research, vol. 74, pp. 59 - 109, 2004. http://dx.doi.org/10.3102/00346543074001059

[5] M. L. Maehr and H. A. Meyer, "Understanding motivation and schooling: Where we've been, where we are, and where we need to go," Educational Psychology Review, vol. 9, pp. 371 - 409, 1997. http://dx.doi.org/10.1023/A:1024750807365

[6] J. E. Ormrod, Educational Psychology: Developing Learners, Pearson Education, 2007.

[7] [7] UNESCO, "UNESCO Science Report 2010: The Current Status of Science around the World." UNESCO Publishing, Paris, 2010.

[8] C. H. Major and B. Palmer, "Assesing the Effectiveness of Problem-Based Learning in Higher Education: Lessons from the Literature." Academic Exchange Quarterly, vol. 5, no. 1, pp. 4-9, 2001 .
[9] J. W. Thomas, "A review of research on Project-Based Learning," March 2000. [Online]. Available: http://www.bobpearlman.org/BestPractices/PBL_Research.pdf. [Accessed 24 March 2014].

[10] B. F. Jones, C. M. Rasmussen and M. C. Moffitt, Real-life problem solving: A collaborative approach to interdisciplinary learning. Psychology in the classroom, Washington: American Psychological Association, 1997.

[11] J. W. Thomas, J. R. Mergendoller and A. Michaelson, Projectbased learning: A handbook for middle and high school teachers, Novato, CA: The Buck Institute for Education, 1999.

[12] I. de Vere, "Developing creative engineers: a design approach to engineering education." International Conference on Engineering and Product Design Education, Brighton, 2009.

[13] R. Zolin, R. Fruchter and R. E. Levitt, "Realism and Control: Problem-Based Learning Programs as a Data Source for WorkRelated Research," International Journal of Engineering Education, vol. 19, no. 6, pp. 788-798, 2003.

[14] P. J. Velasco Quintana, R. M. Rodríguez Jiménez, M. J. Terrón López and M. J. García García, "La coordinación del profesorado: un elemento clave para la evaluación por competencias," Revista de docencia Universitaria, vol. 10, no. 3, pp. 265-284, 2012.

[15] Y. Blanco Archilla, M. J. Terrón López and M. J. García García, "Developing a key skills guide and assessment criteria for ICT degrees," in 4th Engineering Conference "Engineering" 2007 Innovation and Development, Covilha (portugal), 2007.

[16] A. Fernández Santander, M. J. García García, B. Saez Pizarro and M. J. Terrón López, "Development and Assessment of Key Skills in Undergraduate Students: An action-research experience," Higher Learning Research Communications, vol. 2, no. 1, pp. 3249, March 2012.

[17] M. J. Terrón López and M. J. García García, «Assessing Transferable Generic Skills in Language Degrees,» de Competency-based Languaje Teaching in Higher Education, Dordrecht, Springer, 2012, pp. 151-167.

[18] M. J. Terrón López and M. J. García García, "Key skills development through students learning activities," in International Technology, Education and Development Conference (INTED), Valencia, 2010.

\section{AUTHORS}

M. J. Terrón-López is teacher at the School of Architecture, Engineering and Design, Universidad Europea de Madrid, 28670-Villaviciosa de Odón, Spain (e-mail: m_jose.terron@uem.es).

M.J. García-García is the Director of Student Services at the School of Architecture, Engineering and Design, Universidad Europea de Madrid, 28670-Villaviciosa de Odón, Spain (e-mail: mariajose.garcia@uem.es).

P. J. Velasco-Quintana is the Head of the Department of Science, Informatics and Communications at the School of Architecture, Engineering and Design, Universidad Europea de Madrid, 28670-Villaviciosa de Odón, Spain (e-mail: pjulia.velasco@uem.es).

M. C. Gaya-López is the director of the ICT area at the School of Architecture, Engineering and Design, Universidad Europea de Madrid, 28670-Villaviciosa de Odón, Spain (e-mail: mcruz@uem.es).

J. J. Escribano-Otero is the academic director of the School of Architecture, Engineering and Design, Universidad Europea de Madrid, 28670-Villaviciosa de Odón, Spain (e-mail: juanjose.escribano@uem.es).

This article is an extended and modified version of a paper presented at the EDUCON2015 conference held at Tallinn University of Technology, Tallinn, Estonia, 18-20 March 2015.This work was supported in part by Universidad Europea de Madrid. Submitted, 09 March 2015. Published as resubmitted by the authors on 18 June 2015 . 